\title{
Passivation of chalcopyrite in hydrodynamic-bioleaching
}

\author{
Institute of Mine Reclamation Technology, Mine Reclamation Corporation, Wonju 26464, Republic of Korea; *Corresponding author, \\ E-mail: jayhp@mireco.or.kr
}

(Received: October 23, 2018; Revised accepted: November 28, 2018)

https://doi.org/10.18814/epiiugs/2018/018018

Worldwide Cu deposits mainly exist in the form of lowgrade chalcopyrite $\left(\mathrm{CuFeS}_{2}\right)$. Bioleaching has exhibited significant potential for Cu recovery, but the low recovery performances of chalcopyrite bioleaching has limited its commercialization. Furthermore, the mechanisms and the reaction pathways of chalcopyrite are excessively diverse and complex, therefore require a careful review to elucidate the unclear albeit significant points. A critical reason for the poor Cu recovery in chalcopyrite bioleaching to date is the occurrence of passivation layers along with oxidative leaching. The passivation layers are too thin to be directly observed and consist of various compounds including jarosite. This study also discussed several technical solutions to address the passivation issues; those include utilization of thermophilic microorganism, external electrodes, photocatalysts as well as physical removal or inhibition of jarosite.

\section{Introduction}

Bioleaching is the extraction technique of useful metals from ores by using microorganisms. This environmentally friendly technology is suitable for retrieving low-grade metals (Debernardi and Carlesi, 2003; Panda et al., 2015; Zhao et al., 2015). It is also a popular method that is applied for $\mathrm{Cu}$ recovery since the environmental pollution continues and copper ores that are available today are of low grade (Schippers et al., 2014; Panda et al., 2015). Specifically, Cu recovery by using bioleaching was first commercialized in 1950s (Panda et al., 2015). However, the bioleaching of chalcopyrite that comprises most of the remaining copper ores that are available today has still not been commercialized since chalcopyrite is highly chemically resistant and generates passive layers during the leaching process (Debernardi and Carlesi, 2003). Nevertheless, it is extremely important to develop economical chalcopyrite bioleaching technologies since most of the remaining copper ores around the world are of low grade (Feng et al., 2014).

$\mathrm{Cu}$ bioleaching technologies are categorized into heap bioleaching and bioleaching using an agitation tank. Among these methods, the heap bioleaching of secondary copper sulfide is widely used in practice (Clark et al., 2006; Zou et al., 2013; Schippers et al., 2014; Panda et al., 2015). Specifically, $8 \%$ of the total world Cu production in 2010 was produced through bioleaching. Among the world's biggest cop- per producers, Chile and Peru produced $42 \%$ and $33 \%$ of the worldwide $\mathrm{Cu}$, respectively, through bioleaching in 2014 (Panda et al., 2015). Given that the need for better technologies continues to grow worldwide for more efficient $\mathrm{Cu}$ recovery from low-grade sulfide ores, bioleaching technologies are increasingly widely applied around the world. Currently, bioleaching is commonly applied for secondary copper ore leaching while chalcopyrite bioleaching is mainly at a pilot stage or applied in small-scale test plants (Panda et al., 2012, 2015).

Figure 1 depicts the scheme of heap bioleaching that is the most generally applied method. The microaerophilic/eosinophilic ferrooxidant/sulfur-oxidizing microorganisms are injected into a heap of relatively regular-sized copper ores. Bioleaching solution including microorganisms, nutrients, a $\mathrm{pH}$ adjuster, and a reducing agent is sprinkled over the top of the heap, and air is supplied to the bottom of the heap to grow anaerobic microorganisms and extract metals. The leachate obtained at the lower part of the heap is collected for the latter process (solvent extraction and electro-winning (SX-EW)) to extract high grade $\mathrm{Cu}$. A leach pad is installed at the bottom of the heap to prevent the pregnant solution from permeating into soil or joining underground water. The collected leachate is returned to the top of the heap for reuse until the liquid $\mathrm{Cu}$ concentration reaches a desired level. In a few regions affected by heavy rainfalls, the heap is shielded with a large cover to prevent rain from coming into contact with the heap (Panda et al., 2015).

There is a paucity of information on the passivation layer of chalcopyrite, and thus there is significant room for questions on existing theories and academic viewpoints. Given this situation, an effective method to approach the issue involves reviewing and reorganizing frequently cited recent studies. The study reviewed and summarized recent studies related to the characteristics of chalcopyrite, the role of microorganisms influencing chalcopyrite oxidation and the passivation layer of chalcopyrite during bioleaching. This offers a detailed description of the passivation layer formation and consequent reactions and suggests potential solutions. This study aims to contribute to the acceleration of the commercial development of chalcopyrite bioleaching by suggesting the major research topics.

\section{Electrochemical Properties of Chalcopyrite}

Chalcopyrite has an approximate density of $4.2 \mathrm{~g} / \mathrm{cm}^{3}$ and its chemical formula corresponds to $\mathrm{CuFeS}_{2}$. The substance consists of sulfur atoms combined with metal atoms including $\mathrm{Cu}$ or $\mathrm{Fe}$ (Debernardi 


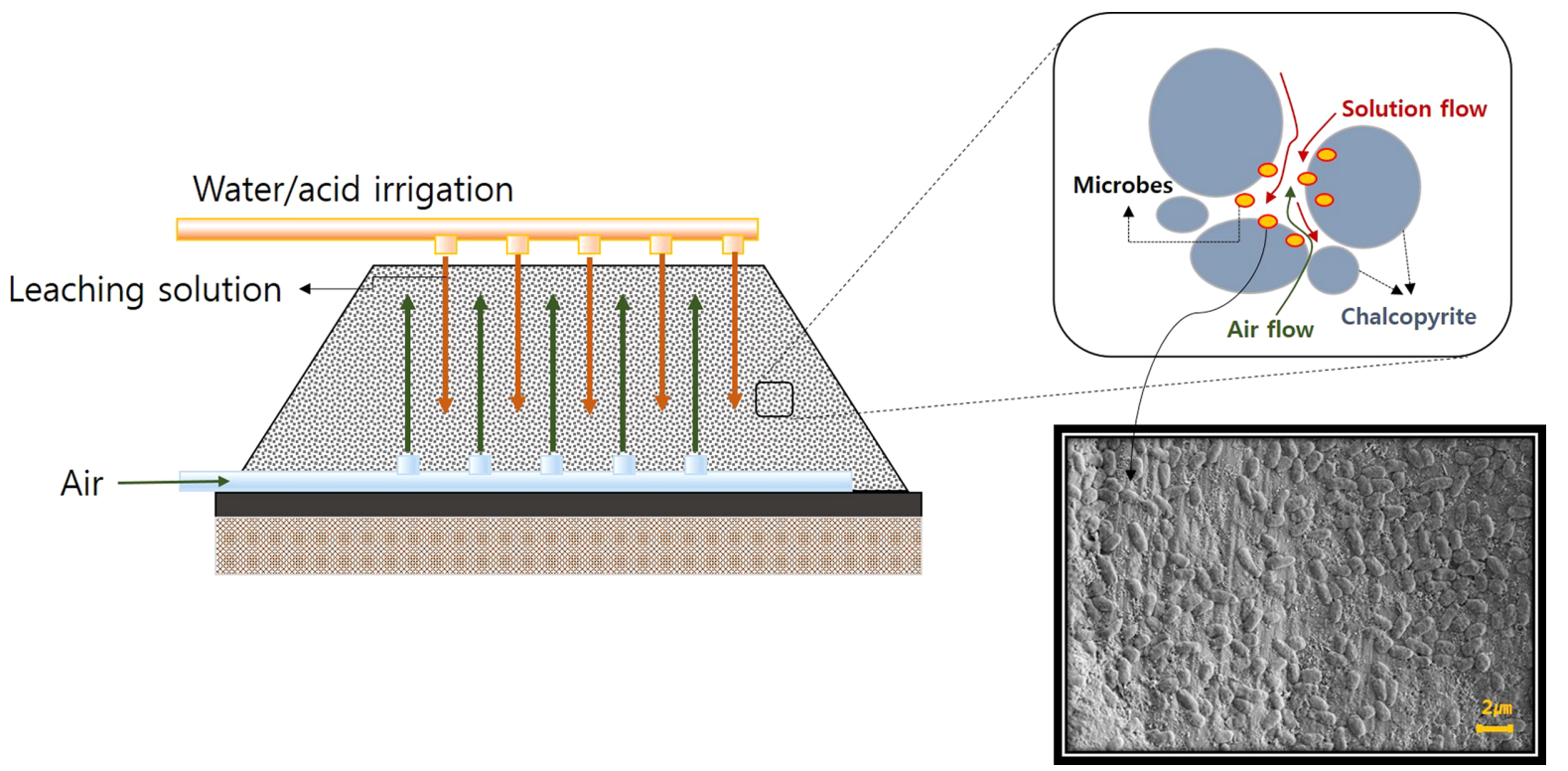

Figure 1. Basic concept of a heap bioleaching process together with a photograph of microbes on leaching ore surfaces. The illustration was modified from Panda et al. (2015).

and Carlesi, 2013). Its lattice energy is approximately $17,500 \mathrm{~kJ}$ and significantly exceeds that of other minerals such as pyrite, covellite, and chalcocite approximately $3,000-4,000 \mathrm{~kJ}$. Chalcopyrite is also more chemically resistant, and thus it is difficult to recover desired metals when compared to other sulfide minerals (Debernardi and Carlesi, 2013). Another significant property of chalcopyrite is that it is a natural semiconductor material (Crundwell, 1988). In several conductive metallic compounds, the conduction band and valence band overlap with each other, and electrons in the valence band easily move to the conduction band as free electrons. Conversely, this movement of electrons is relatively more restricted in semiconductor materials such as chalcopyrite (Crundwell, 1988; Debernardi and Carlesi, 2013; Li et al., 2013; Crundwell, 2015). This is because a band gap exists between 1) the valence band that contains bonded electrons, and 2) the conduction band that contains unbonded free electrons. An energy gap termed as 'band gap' lies between the two bands, and it is not possible for electrons to remain in the gap. Furthermore, Fe electrons in chalcopyrite are mainly observed around the anti-bonding orbital in the conduction band. Conversely, the bonding orbital of $\mathrm{Cu}$ electrons exists in the valence band. Thus, $\mathrm{Cu}$ is strongly bonded with $\mathrm{S}$ in the crystals. The gap between the conduction band and valance band is approximately $0.6 \mathrm{eV}$ (Crundwell, 1988; Debernardi and Carlesi, 2013; Vargas et al., 2014; Crundwell, 2015).

\section{Microbial Oxidation}

Generally, microbes require carbon sources, energy sources, and nutrients for survival and reproduction (Hatzikioseyian and Tsezos, 2006; Lee, 2017a). Those heterotrophic microorganisms are used for aerobic biodegradation, such as composting or sewage treatment, gain energy required for reproduction and survival by using organic matters as carbon sources and electron donor and dissolved oxygen $\mathrm{O}_{2}$ as a final electron acceptor (respiration). Conversely, aerobic microor- ganisms (autotrophs) involved in bioleaching mainly use $\mathrm{CO}_{2}$ as carbon source and $\mathrm{Fe}^{2+}$ and $\mathrm{S}$ as electron donors. These types of organisms obtain energy by using $\mathrm{O}_{2}$ as a final electron acceptor. In chalcopyrite bioleaching, microorganisms mainly oxidize $\mathrm{Fe}$ in ores to use it for proliferation and growth ( $\mathrm{S}$ is also used although this provides lesser energy when compared to $\mathrm{Fe}$ oxidation), and the remaining $\mathrm{Cu}$ is chemically extracted. The amount of energy or proliferation produced by autotrophic microorganisms is less than that of heterotrophs. Nevertheless, it is important to provide energy sources including $\mathrm{Fe}, \mathrm{S}$, and $\mathrm{Cu}$, final electron acceptor $\mathrm{O}_{2}$, and additional nutrients other than the carbon source $\mathrm{CO}_{2}$ that is required for proliferation (Lee, 2017a).

Figure 2 shows a set of chain reactions caused by the metabolism of aerobic microorganisms, namely, $\mathrm{Fe}^{3+} / \mathrm{Fe}^{2+}$ redox reactions and sulfide ore elution reaction. Fe is more easily oxidized and extracted than $\mathrm{Cu}$

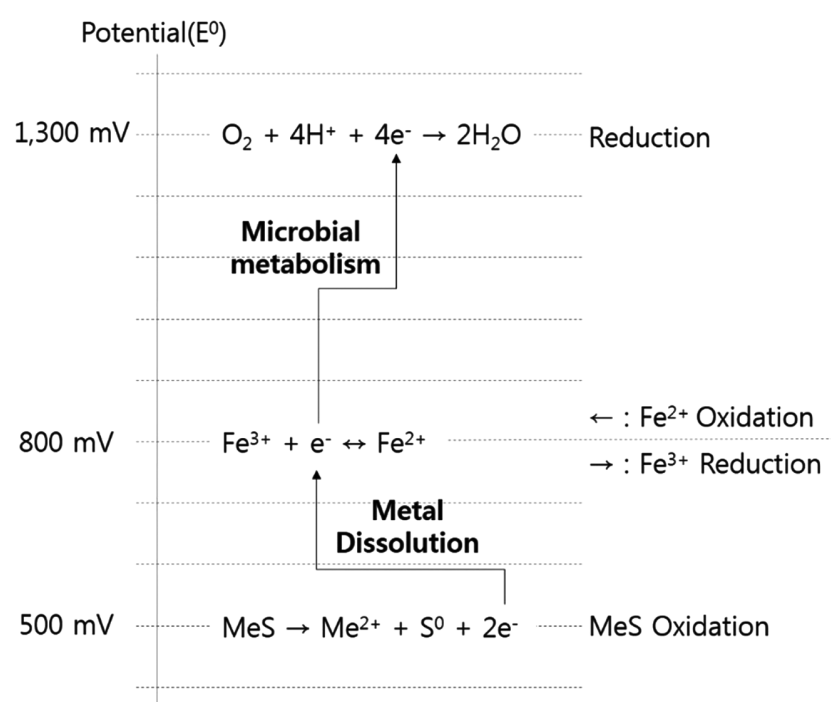

Figure 2. Microbial dissolution of metal sulfide by Fe ion oxidation/ reduction. Redrawn from Vargas et al. (2014). 
because free electrons of $\mathrm{Fe}$ in ores are in the conduction band level. The reduction of $\mathrm{O}_{2}+\mathrm{H}^{+} \rightarrow \mathrm{H}_{2} \mathrm{O}$ that frequently occurs in aerobic microorganisms produces high energy that can even recover $\mathrm{Cu}$ in the chalcopyrite. The metabolic reaction reduces oxygen molecules by electrons generated from $\mathrm{Fe}^{2+}$ oxidation.

Bioleaching recovers metals from sulfide ore (MeS). Specifically, chalcopyrite bioleaching retrieves $\mathrm{Cu}$ by using mesophilic and thermophilic microorganisms that oxidize $\mathrm{Fe}^{2+}$ and $\mathrm{S}$. In this case, the environment should be maintained as highly acidic, thereby allowing ferrooxidant microorganisms in the bioleaching process to cope with the hyperacidic environment (this also requires a significant amount of $\mathrm{H}^{+}$to stimulate the oxygen reduction and leaching process in an aerobic condition).

There are varying interpretations of the leaching reaction of chalcopyrite (Debernardi and Carlesi, 2013), and the reaction equation that is most frequently cited by extant studies is expressed as Equation (1) as follows (Dutrizac, 1981; Hackl et al., 1995; Hiroyoshi et al., 2002):

$$
\mathrm{CuFeS}_{2}+4 \mathrm{Fe}^{3+} \rightarrow \mathrm{Cu}^{2+}+5 \mathrm{Fe}^{2+}+2 \mathrm{~S}^{0} .
$$

In the above equation, $\mathrm{Fe}$ and $\mathrm{Cu}$ are oxidized and extracted from chalcopyrite, and $\mathrm{S}$ is oxidized into $\mathrm{S}^{0}$ (elemental sulfur). The oxidization reaction occurs in parallel with the reduction of $\mathrm{Fe}^{3+}$. In the process, $\mathrm{Fe}^{3+}$ is depleted and is ultimately exhausted if the extraction continues without additional $\mathrm{Fe}^{3+}$ supply. In this case, energy and $\mathrm{Fe}^{3+}$ required for the extraction reaction are produced and supplied through a set of microbial reactions as given by Equation (2) as follows (Debernardi and Carlesi, 2013; Vargas et al., 2014):

$$
\begin{aligned}
& \mathrm{O}_{2}+4 \mathrm{H}^{+}+4 \mathrm{e}^{-} \rightarrow 2 \mathrm{H}_{2} \mathrm{O}, \\
& \mathrm{Fe}^{2+} \leftrightarrow \mathrm{Fe}^{3+}+\mathrm{e}^{-} .
\end{aligned}
$$

As shown in the Equation (2), one of the most important roles of the microorganisms in chalcopyrite bioleaching involves oxidizing the product of Equation (1) $\mathrm{Fe}^{2+}$ to generate $\mathrm{Fe}^{3+}$ to sustain the extraction reaction (Zeng et al., 2010; Li et al., 2014). Electrons resulting from the oxidation of $\mathrm{Fe}^{2+}$ are used for the reduction of $\mathrm{O}_{2}$, which exhibits a high reduction potential. Given that $\mathrm{O}_{2}$ is reduced into water by microorganisms, a high level of energy is generated, and this oxidizes $\mathrm{Fe}^{2+}$ to produce $\mathrm{Fe}^{3+}$. This implies that it is possible to extract $\mathrm{Cu}$ and S from chalcopyrite (Vargas et al., 2014). Even small metal particles on the surface of ores are extracted because products of reaction are concentrated in the system of or around microorganisms. Another instrumental role of microorganisms corresponds to the oxidization of the other product of extraction $\mathrm{S}^{0}$ (Debernardi and Carlesi, 2013; Li et al., 2013). Microorganisms prevent the accumulation of $S^{0}$ on the surface and reduce $\mathrm{pH}$, thereby ensuring that the extraction reaction is active.

Various mechanisms involved in chalcopyrite bioleaching are highly complex and are not completely elucidated. Furthermore, there is a paucity of understanding with respect to the effects of microorganisms on metal recovery. Therefore, it is necessary to demonstrate the reaction pathway and energy that govern $\mathrm{Cu}$ recovery from chalcopyrite and low leaching rate (Debernardi and Carlesi, 2013). There are various approaches and techniques to analyze and understand the mechanism of bioleaching including thermodynamic perspective (Hatzikioseyian and Tsezos, 2006), reaction kinetics (Ojumu et al., 2006), and mechanical modeling (Peterson, 2010). Among the aforementioned, the electrochemical method is considered as the most effective and significant method (Debernardi and Carlesi, 2013; Khoshkhoo et al., 2014; Vargas et al., 2014).

\section{Role of Microorganisms in Chalcopyrite Leaching}

Previously, microbial extraction mechanisms in bioleaching were classified into indirect and direct types based on the reaction characteristics of microorganisms involved in Fe oxidization (Rohwerder et al., 2003). Currently, they are classified into contact, non-contact, and cooperative mechanisms based on whether microorganisms are attached to the ore surface (Watling, 2006). The coupling reaction between $\mathrm{Cu}$ oxidation and $\mathrm{Fe}^{3+}$ reduction is the key mechanism, in which the role of bioleaching microorganisms is to regenerate $\mathrm{Fe}^{3+}$ though oxidation of $\mathrm{Fe}^{2+}$ (Li et al., 2014; Lee, 2017a). The indirect mechanism refers to the reaction in which microorganisms oxidize $\mathrm{Fe}^{2+}$ into $\mathrm{Fe}^{3+}$ in solution. Conversely, the direct mechanism is a reaction in which microorganisms directly oxidize sulfide without the $\mathrm{Fe}^{3+} / \mathrm{Fe}^{2+}$ oxidization. Among the two mechanisms, the indirect mechanism is thoroughly investigated. The entire process of reproduction of $\mathrm{Fe}^{3+}$ through $\mathrm{Fe}^{2+}$ oxidation is described in the study as a result of the indirect mechanism. Essentially, the mechanism is almost similar to that of chemical extraction with the only exception that it sustains the chemical leaching through $\mathrm{Fe}^{2+}$ oxidization by microorganisms. Conversely, only a few extant studies empirically demonstrated the direct mechanism (Shipper et al., 2014; Panda et al., 2015). In the contact mechanism, $\mathrm{Fe}^{2+}$ is oxidized through the enzymatic reaction of microorganisms attached to the ore surface (Rodríguez et al., 2003). In the initial stage, microorganisms are reversibly attached to the ore surface through a static or other type of physical reaction (the cilia on the surface of microorganisms). Microorganisms form a community over a period of time, and the microbial community gets more firmly fixed on the surface by forming an extracellular polymeric substance (EPS) (Rodríguez et al., 2003). Specifically, EPS is a mucous substance secreted from microorganisms, and it increases the safety of microbial ecosystems by protecting microbial communities from the external environment. It can also oxidize $\mathrm{Fe}^{2+}$ or sulfide ( $\mathrm{Li}$ et al., 2013). Furthermore, $\mathrm{Fe}^{2+}$ or sulfide is oxidized by a kingdom of microorganisms without EPS although EPS is capable of accumulating substances associated with the reaction, and thus effectively recovers even extremely tiny metal pieces in ores (Kinzlera et al., 2003; Sand and Gehrke, 2006). Although EPS appears to play a central role in significantly enhancing the bioleaching efficiency for low-grade ores, an excessive amount of EPS can reduce the ore leaching performance (Zeng et al., 2010, 2011). The proliferation of attached biofilm is significantly influenced by attachment targets such as the contact area of the ore surface, pore structure, bond energy, and affinity of microorganisms (electrostatic attraction or repulsion by surface potential) other than the solution conditions such as flow velocity, temperature, and pH (Rodríguez et al., 2003; Li et al., 2013). The non-contact mechanism as suggested by its name is a reaction in which $\mathrm{Fe}^{2+}$ is oxidized by microorganisms (Suspended cell) (Watling, 2006; Li et al., 2013). Finally, in the cooperative mechanism, attached and suspended microorganisms form a type of symbiosis when the biofilm is saturated (Watling, 2006; Li et al., 2013), and this contrib- 


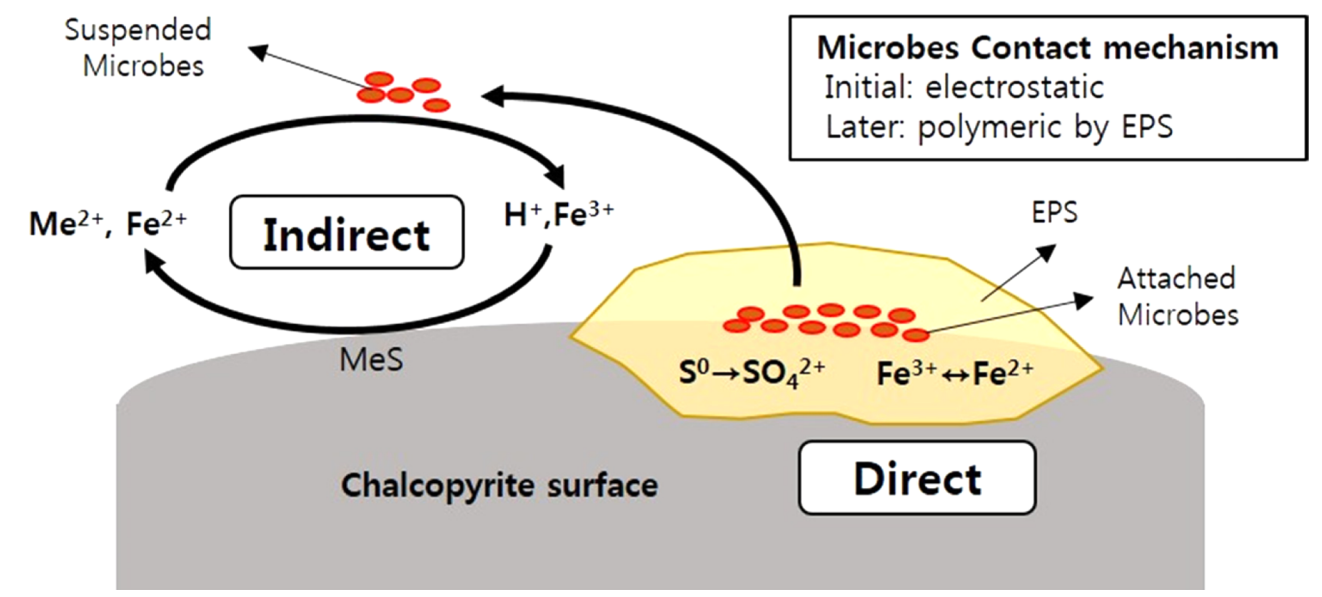

Figure 3. Mechanisms of microbial bioleaching on the surface of chalcopyrite. Adapted from Li et al. (2013).

utes to enhancing bioleaching efficiency. Figure 3 shows the types of microbial reactions.

In terms of microbial species, the effect of bioleaching significantly increases and especially when thermophiles or mixed microorganisms are injected. This is potentially because the former holds a significant amount of energy available, and the latter offers significant benefits for adaptation and proliferation in relation to ecological stability when compared to a single species (D'Hugues et al., 2002; Ahmadi et al., 2010; Zeng et al., 2010, 2011). The leaching effect is significantly extremely high when thermophiles react with ultrafine grounded ores (the leaching reaction is further stimulated due to the increased specific surface area when the size of the ore particle becomes finer). Conversely, mesophilic microbes demonstrate a lower bioleaching effect when compared to that of thermophiles (Olson et al., 2003).

In real settings, a characteristic distinguishes bioleaching from chemical leaching, namely it requires a significantly long period of adaptation until microorganisms adapt to the reaction system and the microbial population reaches a certain size. Thus, the preliminary operation period can be extended.

The general survival conditions of microbes include appropriate temperature (water content), $\mathrm{pH}$, temperature, low content of toxins or inhibitors, sufficient energy sources, and nutrients (Vilcáez et al., 2008; Panda et al., 2015). Autotrophs that are frequently used for bioleaching are heavily dependent on minerals ( $\mathrm{Fe}$ and $\mathrm{S}$ ) and oxidation during catabolism (the process of obtaining energy through reactions such as respiration), and thus their oxidation-reduction electric potential is extremely important (Lee, 2017b). In order to ensure successful bioleaching, it is important to set the right oxidation-reduction electric potential for the reaction solution (for e.g., the $\mathrm{Fe}^{3+} / \mathrm{Fe}^{2+}$ concentration ratio). Additionally, smaller-sized ores are better since the specific surface area increases.

The other major components of chalcopyrite bioleaching correspond to lower electric potential when compared to the leaching of other similar types of ores, high temperature, and an adequate amount of catalyst (Ag). Specifically, components that are specifically important include the $\mathrm{Fe}^{3+} / \mathrm{Fe}^{2+}$ concentration ratio and electric potential (Vargas et al., 2014). Bioleaching consumes a significant amount of $\mathrm{Fe}^{3+}$ on the reduction that is coupled with oxidation in most cases. Reduced $\mathrm{Fe}^{2+}$ is used as an energy source for eosinophilic ferrooxidant microorgan- isms, and thus an adequate amount of $\mathrm{Fe}^{2+}$ is also required. $\mathrm{The}^{3+} / \mathrm{Fe}^{2+}$ concentration ratio is significant because the ratio ultimately determines the electric potential of solution (assuming that the effect of $\mathrm{Cu}^{2+}$ ions is ignored). An electrochemically high electric potential implies that it stimulates oxidative leaching through the relatively higher concentration of $\mathrm{Fe}^{3+}$ when compared to that of $\mathrm{Fe}^{2+}$. Conversely, low electric potential indicates that microbial ferrooxidation reaction is stimulated by a higher concentration of $\mathrm{Fe}^{2+}$ when compared to that of $\mathrm{Fe}^{3+}$. The following chapter discusses the concept of controlling the speed of sulfide ore bioleaching through the $\mathrm{Fe}^{2+} / \mathrm{Fe}^{3+}$ concentration ratio in further detail.

\section{Formation of the Passivation Layer in Chalcopyrite}

The most generally used reaction equation related to the leaching of chalcopyrite is given below (Debernardi and Carlesi, 2013; Li et al., 2013; Panda et al., 2015):

$$
\mathrm{CuFeS}_{2}+4 \mathrm{Fe}^{3+} \rightarrow \mathrm{Cu}^{2+}+5 \mathrm{Fe}^{2+}+2 \mathrm{~S}^{0} .
$$

In the oxidative leaching of $\mathrm{Fe}$ and $\mathrm{Cu}$ in chalcopyrite in relation to passivation, the chemical reaction of sulfur in chalcopyrite is extremely significant. Equation (3) indicates that $\mathrm{S}$ in the ore is oxidized into $\mathrm{S}^{0}$ (elemental sulfur), and a significant amount of the generated $\mathrm{S}^{0}$ accumulates on the ore surface. Ferrooxidant/sulfur-oxidizing microorganisms can ultimately oxidize $\mathrm{S}^{0}$ again into $\mathrm{SO}_{4}{ }^{2-}$ and dilute it. The reaction prevents over accumulation of $\mathrm{S}^{0}$ (Debernardi and Carles, 2013; Li et al., 2013), and this is described by the following Equation (4):

$$
2 \mathrm{~S}+3 \mathrm{O}_{2}+2 \mathrm{H}_{2} \mathrm{O} \rightarrow 2 \mathrm{SO}_{4}^{2-}+4 \mathrm{H}^{+} .
$$

It is excessively complex to explain the actual reaction of passivation layer formation on chalcopyrite with general equations such as the aforementioned expression. The general leaching reaction focuses on the oxidation of metals, and thus it does not elaborate reactions that occur on the ore surface such as the passivation layer. Hammer et al. (2006) suggested a 3-stage reaction in relation to chalcopyrite passivation layer.

Elemental sulfur forms a range of chemical bonds, and past studies 
empirically demonstrated that $\mathrm{S}_{8}$ is the most common compound form with the highest bonding stability (Klauber et al., 2001; Parker et al., 2008). The formation of passivation layer occurs in the same reaction conditions as those for $\mathrm{Cu}$ or $\mathrm{Fe}$ leaching. In electrochemical terms, the reaction is controlled through electric potential by using the $\mathrm{Fe}^{3+}$ / $\mathrm{Fe}^{2+}$ ratio. However, the inhibition of the passivation layer formation through electric potential inevitably simultaneously inhibits oxidative leaching.

In reality, $\mathrm{S}^{0}$ is frequently discovered in residues and potentially does not correspond to the major substance that constitutes the final passivation layer. A few studies reported that the effect of $S^{0}$ on noncontact microorganisms exceeds the effect of those contacting the ore. Hackl et al. (1995) estimated that $\mathrm{S}^{0}$ features high porosity, and therefore does not significantly affect the leaching processes, such as the inhibition of ion proliferation, although it accumulates over the surface. The issue is that jarosite also occurs in addition to $\mathrm{S}^{0}$, and it precipitates on the surface over the course of the reaction. The solid sediment blocks the pores of the film of other substances. In turn, the blocking reduces the specific surface area and ultimately undermines the leaching process (Hackl et al., 1995; Klauber, 2008; Debernardi and Carlesi, 2013). Specifically, $\mathrm{S}^{0}$ and jarosite form in different conditions. The latter easily forms since $\mathrm{Fe}^{3+}$ precipitates when the $\mathrm{pH}$ level rises locally. High temperature is another favorable condition for jarosite.

The general jarosite precipitation reaction is given by Equation (5) as follows (Martin et al., 2009; Feng et al., 2014):

$$
\mathrm{K}^{+}+3 \mathrm{Fe}^{3+}+2 \mathrm{SO}_{4}^{2-}+6 \mathrm{H}_{2} \mathrm{O} \leftrightarrow \mathrm{KFe}_{2}\left(\mathrm{SO}_{4}\right)_{2}(\mathrm{OH})_{6}+6 \mathrm{H}^{+} .
$$

In the above equation, $\mathrm{Na}^{+}$is included instead of $\mathrm{K}^{+}$. EPS (Extracellular Polymeric Substance) that is produced by microbial communities themselves, and it also exhibits a leaching inhibition effect other than that of jarosite (Zeng et al., 2010, 2011) although there is no equation that expresses the process to date.

The decline of leaching reaction speed is typically expressed in the form of reaction speed equation. One of the most basic methods to mathematically express the reaction speed associated with chalcopyrite involves establishing the equation by using the concentration of solution ions as a variable. Specifically, several existing studies developed a speed equation based on $\mathrm{H}^{+}$concentration $(\mathrm{pH})$, metal ion con-
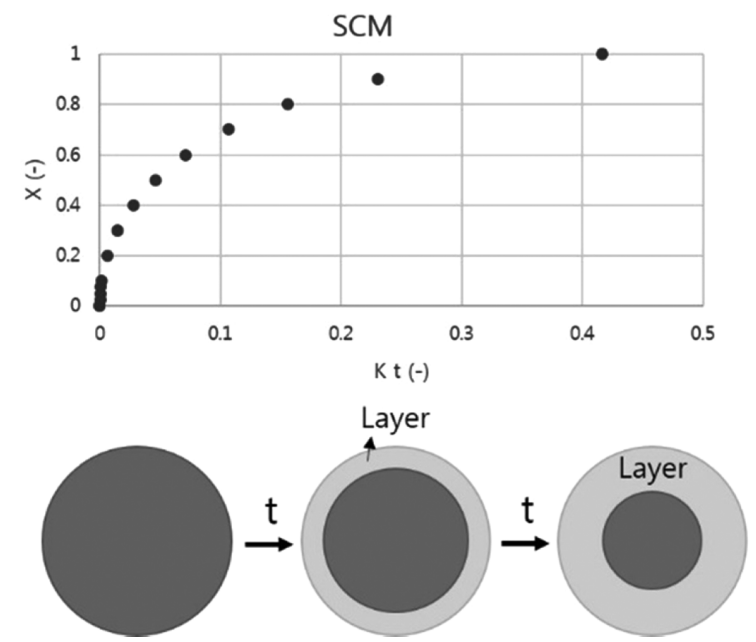

centration, or temperature (Liddell, 1986; Adebayo et al., 2003; Kimball et al., 2010; Li et al., 2010). However, the issue is that these types of speed equations mainly express the chemical reaction speed while the leaching reaction decline caused by the passivation layer corresponds to the issue of inhibited diffusion of leached metals due to the layer. Thus, it is difficult to describe the diffusion inhibition without including an additional diffusion term in the speed equation that solely consists of terms associated with chemical reactions. Conversely, the addition of a diffusion term leads to the issue of considering additional coefficients such as diffusion coefficient or the thickness of the diffusion layer.

The chalcopyrite leaching curve initially draws a parabola in the initial period of reaction although this changes into a straight line with a gentle gradient over the course of time. This is primarily because the reaction material (the amount of ore) changes over the course of leaching. This is expressed via several models. A typical example is the shrinking core model (SCM) that models the reaction of reaction products accumulating on the solid particle surface as solid particles (for e.g., ore shrink) since they are consumed through reactions including leaching (Dutrizac et al., 1978; Camerio and Leão, 2007; Safari et al., 2009). Shrinking in this context indicates that the volume of solid decreases when the solid decreases due to reactions. In SCM, products accumulate on the solid surface over the course of the reaction, and the particle size of solid products is considered as equivalent to the original size of the solid particle. The shrinking particle model (SPM) also simulates the phenomenon in which solid particles reduce and disappear due to the reaction. The SPM is different from SCM because it assumes that products do not accumulate on the solid surface, and thus the total size of solid particles continues to decrease when compared to the original particle size (Aydoğan et al., 2006b; Espiari et al., 2006). The SCM and SPM are expressed as given below:

$$
\begin{aligned}
& \text { SCM: } 1-0.67 \mathrm{X}-(1-\mathrm{X})^{0.67}=k \mathrm{t}, \\
& \text { SPM: } 1-(1-\mathrm{X})^{0.33}=k \mathrm{t} .
\end{aligned}
$$

Here, $\mathrm{t}$ denotes leaching reaction time (s), $k$ denotes the reaction constant $(1 / \mathrm{s})$, and $\mathrm{X}$ denotes the fraction (-) of already leached chalcopyrite. Both models simulate parabolic curves in the initial reaction although the shape varies for each of the curves. In the SCM, products accumulate on the surface layer, and the leaching speed curve is
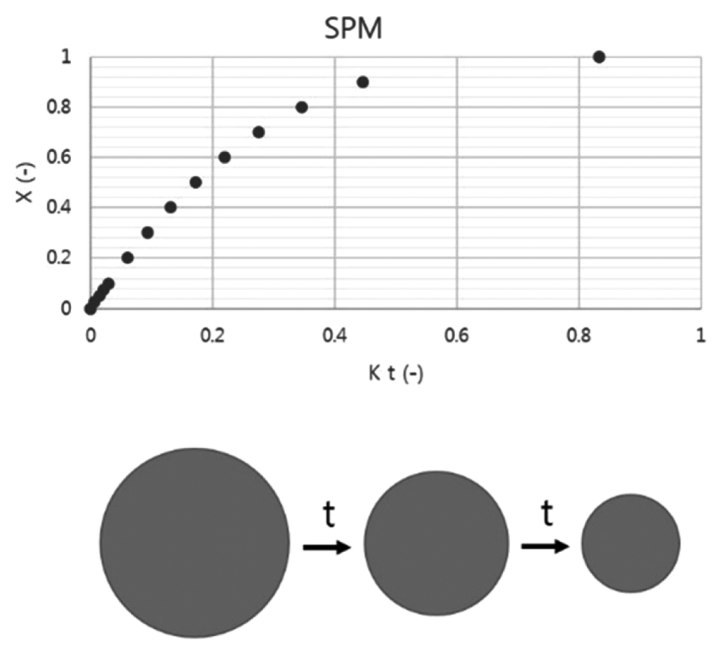

Figure 4. Size variation patterns of solids by shrinking core model and shrinking particle model. Redrawn and adapted from Safari et al. (2009). 
closer to the parabola when the leaching reaction is delayed increasingly over the course of time when compared to SPM. Conversely, the SPM is closer to a straight line when compared with the SCM. Figure 4 shows the schemes of the SCM and SPM.

This is applied to the chalcopyrite passivation layer, and the diffusion of reaction material in the ore is potentially delayed due to the formation of the passivation layer. If the leaching speed is significantly affected, then it is suitable to simulate the leaching curve with SCM (Lee, 2017b). Specifically, Ikiz et al. (2006) determined the fundamental mechanism based on the pattern of the chalcopyrite leaching speed curve. They indicated that the pattern is closest to a curved line when the diffusion through the production layer is high. This implies that it is close to the case in which the leaching speed curve is based on SCM. Additionally, in chalcopyrite bioleaching, metals present in ores continue to be leached and shrink although the SCM is applicable because a few substances including $\mathrm{S}^{0}$ form on the surface. Diverse models are developed based on SCM and SPM to simulate chalcopyrite leaching rate. Several of the models expressed the reaction coefficient $k$ of Equation (6) with a function for $\mathrm{pH}$ or temperature and not with a constant (Dresinger and Abred, 2002; Adebayo et al., 2003; Aydoğan et al., 2006a; Dong et al., 2009).

The pattern of a real leaching curve over the course of time is more complex than the above models. Klauber (2008) summarized the reactions based on the leaching curve into the following four stages:

I) Initial stage where the leaching speed is fast (an ascending linear curve with a steep gradient)

II) $\mathrm{S}^{0}$ continues to accumulate on the ore surface and this begins to affect the leaching process (a parabolic curve in which the gradient becomes gentle over the course of time)

III) Leaching is further delayed due to the surface accumulation of $\mathrm{S}^{0}$ (or the leaching curve corresponds to a linear pattern when the leaching speed increases given that $S^{0}$ is removed)

IV) Jarosite formation wherein the jarosite that is formed attaches to the ore surface, and this causes a significant decrease in leaching (the curve is parabolic with an extremely gentle gradient)

\section{Issue of the Chalcopyrite Passivation Layer}

Chalcopyrite accounts for the majority of $\mathrm{Cu}$ ores that are currently available around the world. It is difficult to leach the low-grade ore since it is chemically resistant and the leaching speed is low (Debernardi and Carlesi, 2013; Panda et al., 2015). Specifically, Cu bioleaching is widely applied because it is effective for low-grade secondary $\mathrm{Cu}$ sulfide ores, such as chalcocite, although it is not extremely effective with respect to chalcopyrite (Panda et al., 2015). One of the most direct causes that affect bioleaching efficiency corresponds to the passivation layer that is formed over the course of leaching in addition to the significant chemical resistance of the ore (Debernardi and Carlesi, 2013; Li et al., 2013; Nicol, 2017). The term passivation implies that the chemical reaction of a metal substance reduces in a certain condition. A passivation layer refers to the film of substances that is coated over the ore and causes passivation. In reality, the thickness of the passivation layer is atomic-thin, and it is extremely difficult to observe with highly advanced surface analysis technologies (Debernardi and Carlesi, 2013). When a passivation layer forms on chalcopyrite, $\mathrm{Cu}$ oxidation and recovery from ores is significantly affected. Most of studies agree that it is imperative to resolve the problem of passivation layer to ensure successful chalcopyrite bioleaching (Li et al., 2013; Nicol, 2017).

Although it is estimated that the passivation layer of chalcopyrite consists of various substances, it is almost certain that sulfide comprises the passivation layer based on the stoichiometric analysis of existing leaching experiments (Debernardi and Carlesi, 2013; Li et al., 2013). However, it is not easy to conclusively identify the substances and their characteristics because the substances that form the layer exhibit non-stoichiometric properties that are not described by fixed formulae. Based on the results of extant studies, the passivation layer of chalcopyrite serves as an insular that blocks the flow of ions necessary for reactions or a semiconductor with a significant band gap, thereby interfering with $\mathrm{Cu}$ leaching (Debernardi and Carlesi, 2013). There are several substances comprising the passivation layer that cause a decline in the leaching efficiency. Existing studies observed that jarosite and $\mathrm{S}^{0}$ (elemental sulfur) exhibit a significant effect thereon, and the effect of jarosite is significant (Li et al., 2013). Additionally, $\mathrm{S}^{0}$ affects the leaching performance to a lesser degree although it is difficult to remove due to its chemical stability.

The observation of chalcopyrite passivation layer through surface analysis is not highly reliable. Parker et al. (1981) initially observed a film of polysulfide forming across the chalcopyrite surface, and they detected the same through the rise and fall of electric current with respect to the electric potential. The current density is largely variable based on the changes in the electric potential. The current density should increase with increases in the electric potential in a normal oxidative leaching process. However, the density rapidly declines when a passivation layer occurs (Viramontes-Gamboa et al., 2013).

\section{Solution for the Leaching Performance Decline caused by the Passivation Layer}

Solutions for the decline in leaching performance include the following: increasing the speed of leaching performance, inhibiting the formation of passivation layer, and removing the substances that form the existing passivation layer. Logically, the optimal solution involves the application of a technology that technically considers all the factors. The techniques suggested by studies so far include: (1) the application of highly active thermophiles (D'Hugues et al., 2002; Zheng et al., 2009; Ahmadi et al., 2011; Zeng et al., 2011; Zhao et al., 2015), (2) injecting additives such as $\mathrm{Ag}$ or external electrode materials (Holems et al., 1995; Nakazawa et al., 1998; Hiroyoshi et al., 2002; Córdoba et al., 2008; Dixon et al., 2008; Ghahremaninezhad et al., 2015; Zhao et al., 2016), and (3) minimizing or removing the formation of jarosite through $\mathrm{pH}$ control or additional physical processes (Feng et al., 2014). This chapter introduces the technologies and discusses their effects.

\section{Physical Removal of Jarosite}

Klauber (2008) indicated that the formation and coating of jarosite on the ore surface is the main cause of leaching decline, and suggested three options to remove jarosite: 1) preventing the formation of jarosite in the early stage, 2) inducing already generated jarosite to 
deposit to prevent it from getting attached to the ore surface, and 3) establishing an additional process to remove jarosite. In order to ensure that the first option is successful, it is necessary to establish a condition that inhibits the formation of jarosite in the first place. One of the simplest solutions for this involves consistently maintaining a $\mathrm{pH}$ less than 1. However, in this case, jarosite forms immediately in a few local areas of the environment (for e.g., around a gangue surface) where the $\mathrm{pH}$ level exceeds 1 although $\mathrm{pH}$ is maintained under 1 in theory. When jarosite is formed, it acts as a precursor for more jarosite. Hence, Klauber (2008) argued for the second and the third options to successfully remove jarosite. Thus, an additional process should be established outside the bioleaching reaction system, and the leachate resulting from bioleaching should undergo the process. Jarosite occurring in the leachate during the process is induced to precipitate, and the supernate leachate clear of jarosite is returned to the bioleaching reaction system.

\section{Inhibition of Jarosite Formation through pH Control}

Feng et al. (2014) developed a three-stage pH state bioleaching technology to improve the performance of chalcopyrite bioleaching. The technology uses various $\mathrm{pH}$ conditions and leaching cycles that are suitable for the adaptation and growth of microorganisms, $\mathrm{Cu}$ leaching, and jarosite formation. It minutely controls the $\mathrm{pH}$ level within the $\mathrm{pH}$ range of 1.3-1.0-0.7 based on the time point of leaching. For example, $\mathrm{pH}$ increases slightly at a point where it is necessary to increase the number of microorganisms and decreases at a point that is favorable for the growth of jarosite due to increased $\mathrm{Fe}^{3+}$ to inhibit its proliferation. The method successfully inhibited jarosite growth in contrast to leaving the $\mathrm{pH}$ level unintervened at a certain level. Thus, the period required for preliminary adaptation of microorganisms significantly reduced, and the amount and speed of $\mathrm{Cu}$ elution significantly increased.

\section{Thermophilic Microorganisms}

Another solution to reduce the effect of jarosite involves increasing the activity of thermophiles by creating a high-temperature environment (D'Hugues et al., 2002). Microorganisms are categorized into three types based on their optimal activity temperatures, namely psychrotrophic, mesophilic, and thermophilic microorganisms. Among these, mesophiles and thermophiles are important organisms for bioleaching (Deberardi and Carlesi, 2013; Li et al., 2013). Between the two types, thermophilic microorganisms generate higher energy. The property contributes to increase the efficiency of bioleaching of ores with fire resistance (for e.g., chalcopyrite) and reducing the impact of the passivation layer (Debernardi and Carlesi, 2013). However, researches are still in the process of examining related mechanisms and the manner in which thermophiles reduce the impact of the passivation layer. With respect to thermophilic microorganisms, studies focus on mesophiles (moderately thermophilic microorganisms with the optimal temperature for activity ranging from 40 to $55^{\circ} \mathrm{C}$ ) in relation to chalcopyrite other than Archaea, which is classified as hyperthermophile (extreme thermophiles with the optimal temperature for activity ranging from 55 to $80{ }^{\circ} \mathrm{C}$ ). This is because mesophiles require less energy for increasing the temperature and exhibit an increased tendency to adapt to and survive the bioleaching environment when compared to that of the mesophile Archaea (Zhou et al., 2009).

\section{Additive or External Electrode Material}

A general method to prevent leaching efficiency decline caused by the passivation layer involves injecting materials that can serve as a catalyst or electrode. Specifically, $\mathrm{Ag}$ is a favored research subject as a catalyst since it can form $\mathrm{Ag}_{2} \mathrm{~S}$ on the ore surface when it reacts with $\mathrm{S}$. The advantage of the reaction is that $\mathrm{Ag}_{2} \mathrm{~S}$ easily oxidizes during the leaching reaction (Hiroyoshi et al., 2002; Cordoba et al., 2008; Ghahremaninezhad et al., 2015; Zhao et al., 2016). However, the disadvantage is that $\mathrm{Ag}$ is expensive, and a high concentration of $\mathrm{Ag}$ in a solution creates toxicity. The addition of $\mathrm{SO}_{4}{ }^{2-}$ and $\mathrm{Cl}^{-}$ions was investigated in extant studies although the direct effect of the ions on leaching is known as extremely limited. Even if it exhibits an effect, the effect is not electrochemical and is known to be increasingly associated with structural change in the surface of the ore or the passivation layer due to the presence of ions.

The addition of extra electrode materials for chalcopyrite leaching generates electric current by placing chalcopyrite in contact with other conductor materials. This is known as the galvanic effect (Holmes and Crundwell, 1995; Dixon et al., 2008; Chmielewski and Kaleta, 2011). Pyrite is typically used as additional electrode material. When chalcopyrite is in contact with pyrite, an electric circuit is created due to the high electric potential difference, and the oxidation and leaching of chalcopyrite is easier. Pyrite with a high electrochemical potential serves as a cathode and chalcopyrite with a low electric potential as an anode, and this facilitates oxidation (Fig. 5). The electric current generated at this time between the two electrodes naturally exceeds the current generated only with chalcopyrite without a special cathode. High electric current implies that the oxidation/reduction reactions are extremely active. Activated carbon is another electrode material that is used in addition to pyrite. The electrical conductor material also serves as a cathode and increases the anode leaching of chalcopyrite. Its leaching effect is optimal when the activated carbon concentration in solution corresponds to $2 \mathrm{~g} / \mathrm{L}$ (Nahazawa et al., 1998; Liang et al., 2010).

\section{Electro-assisted Reductive Leaching}

The leaching reaction investigated in the study corresponds to the oxidative leaching of $\mathrm{Cu}$ and $\mathrm{Fe}$ in chalcopyrite into respective $\mathrm{Cu}^{2+}$ and $\mathrm{Fe}^{3+}$. In the process, sulfide is oxidized into $\mathrm{S}^{0}$ or $\mathrm{SO}_{4}{ }^{2-}$. When chalcopyrite is leached when $\mathrm{Fe}$ is present, a passivation layer that

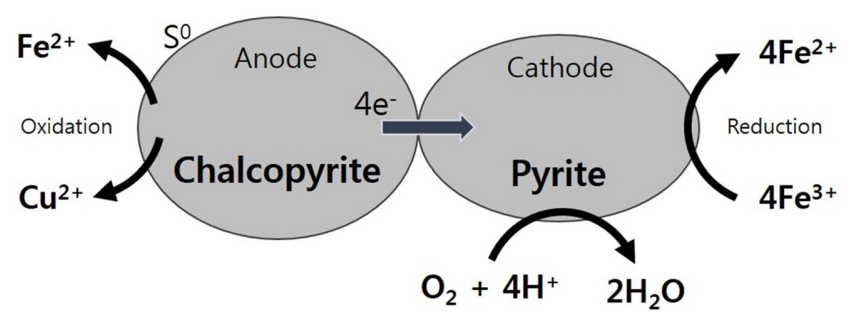

Figure 5. Galvanic interaction during the contact of chalcopyrite and pyrite. Adapted from Li et al. (2013). 
consists of polysulfide is created. Martiníz-Gómez et al. (2016) reported that the formation of passivation layers is prevented by reduction reactions that convert chalcopyrite to easily leached ores, such as $\mathrm{Cu}_{2} \mathrm{~S}$, by using external electrodes as opposed to oxidative leaching. This is potentially because the formation of passivation layer is almost irrelevant to $\mathrm{Cu}$ reduction although it negatively affects leaching in an oxidative environment. The reaction can correspond to a solution to electrochemically reduce the formation of passivation layer, though it is not bioleaching by using microorganisms. There is a paucity of information on the chalcopyrite reduction reaction by using external electrodes when compared to oxidation reactions. However, the information provided by extant studies on the mechanism is summarized

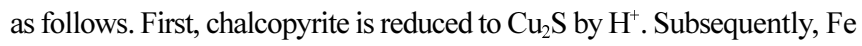
in chalcopyrite is leached, and $\mathrm{S}$ is reduced to $\mathrm{H}_{2} \mathrm{~S}$. This is also termed as non-oxidative leaching since $\mathrm{O}_{2}$ molecules are not involved in the reaction (Nocol and Lazaro, 2003; Debernardi and Carlesi, 2013). Based on Fuentes-Aceituno et al. (2008), the reaction of $\mathrm{H}^{+}$and monoatomic $\mathrm{H}$ with chalcopyrite can ignite the aforementioned reduction reaction. Specifically, the generated $\mathrm{Cu}_{2} \mathrm{~S}$ is reduced to $\mathrm{Cu}$ via the reaction with $\mathrm{H}^{+}$by external electrodes. The expression is as follows:

$$
\mathrm{Cu}_{2} \mathrm{~S}+2 \mathrm{H}^{+}+2 \mathrm{e}^{-} \rightarrow 2 \mathrm{Cu}+\mathrm{H}_{2} \mathrm{~S} \text {. }
$$

In the reaction, it is crucial to maintain the reduction environment of the solution since $\mathrm{H}_{2} \mathrm{~S}$ reacts with $\mathrm{Fe}^{3+}$ otherwise and produces a passivation layer of $\mathrm{S}^{0}$.

\section{Photochemical Reaction}

This is a type of photocatalysis that stimulates oxidative leaching by using visible spectrum. The mechanism is closely associated with the physical property of chalcopyrite being an N-type semiconductor. Electrons around $\mathrm{Fe}$ are mainly concentrated in the conduction band while those around $\mathrm{Cu}$ are concentrated around the valence band. The oxidative leaching of $\mathrm{Cu}$ is stimulated via the application of an energy exceeding $0.6 \mathrm{eV}$ Gap to the gap between the two bands. A technique that employs the mechanism corresponds to the application of energy to $\mathrm{Cu}$ bonding electrons in the valence band to move them to the conduction band (Zhou et al., 2015). Bioleaching uses the energy gained from the cellular respiration of microorganism although the uses of photovoltaic energy facilitate the movement of electrons to a significant higher level. An existing study used the visible spectrum in bioleaching. This facilitates $\mathrm{Cu}$ oxidative leaching and $\mathrm{Fe}^{3+}$ reduction, thereby increasing the $\mathrm{Cu}$ leaching rate by approximately $24 \%$. The disadvantage of the technique is that chalcopyrite must be exposed to light to the maximum possible extent. In order to ensure that this occurs, the ore concentration in solution should be sufficiently low to allow the penetration of light. Furthermore, the reactor should be sufficiently thin for light penetration. It is difficult to apply the method to the heap/dump type reaction that is typically used in bioleaching although an agitation-type reactor that treats grounded ores can potentially correspond to a solution.

\section{Future Research Topics}

Bioleaching is certainly an environmentally friendly cost-effective technology suitable for extracting metals from low-grade ores and recently emerged as a promising alternative given the world-wide scarcity of high grade copper and gold. However, the following problems must be resolved to facilitate wide-ranging application of bioleaching on chalcopyrite.

1) The basic chemical mechanism should be clearly demonstrated. First, the $\mathrm{Cu}$ and $\mathrm{Fe}$ extraction and sulfide reaction in chalcopyrite are extremely diverse and complex, and the mechanisms should be investigated in electrochemical and relation kinetic terms. Recommendations also include developing a model for irregular reaction kinetics on a surface. This should be clearly distinguished from other non-oxidative or redox reaction conditions (Debernardi and Carlesi, 2013). Therefore, appropriate analysis tools are required to investigate reactions, and this should be microscopically observed through spectroscopy.

2) In terms of microbiology, various mechanisms should be further investigated. Specifically, mechanisms of contact, non-contact, and cooperative reactions involving hyperthermophile should be clearly illustrated.

3) From the engineering perspective, it is necessary to advance research and technologies with the further aim of increasing the $\mathrm{Cu}$ leaching speed in chalcopyrite and extraction rate. Studies should endeavor to investigate the electrochemical mechanisms and determine an optimal controlling method for the uses of catalysts (for e.g., silver) or additives (for e.g., activated carbon) other than the existing goal of improving the performance by controlling electric potential (Li et al., 2013). With respect to macroscopic technical issues, such as in heap leaching, it is necessary to identify other factors that influence irregular reactions occurring in bioleaching including $\mathrm{pH}$, oxygen, and temperature gradient and to model the mechanism to optimize the design and operation.

With respect to the passivation layer in chalcopyrite bioleaching, recommendations for future studies include developing a new observation method to directly verify the existence of passivation layer. Various methods that are currently applied for the aforementioned purpose include the conventional microscopic observation or spectroscopy. However, they are not highly reliable. In the indirect observation of passivation layer through voltammetry, the electrode should also be further improved to better reflect the real field characteristics of chalcopyrite leaching. Experimenting with chalcopyrite may produce results that differ from expectation when it contains impurities even if its structure or composition is consistent. This only worsens if additional ores with varying properties are included in the measurement. Given the aforementioned points, it is imperative to define the physical, chemical, and microbiological characteristics of a chalcopyrite sample and solution environment in further detail to ensure that chalcopyrite leaching and passivation layer removal experiments are more realistic. Finally, as suggested by recent studies (Crundwell et al., 2015), it is important to investigate the impact of the natural semiconductor characteristics of chalcopyrite on $\mathrm{Cu}$ leaching speed via a multifaceted approach.

\section{Conclusion}

Chalcopyrite is a semiconductor wherein $\mathrm{Cu}$ electrons exist in the 
valence band and exhibit strong bonds, thereby requiring a significant amount of energy for $\mathrm{Cu}$ oxidative leaching. Additionally, $\mathrm{Fe}^{3+}$ is an effective oxidizing agent for oxidative leaching. The reduction of oxygen molecules by aerobic microorganisms uses electrons obtained through $\mathrm{Fe}^{2+}$ oxidation. This allows the reproduction of $\mathrm{Fe}^{3+}$ that is consumed for the oxidation and extraction process. Ferrooxidant microorganisms used for extraction should correspond to acidophiles since Fe should remain in the form of ions. The oxidation and extraction of sulfide ore consumes a significant amount of $\mathrm{Fe}^{3+}$, and thus the process occurs smoothly in the solution of a high electric potential, namely with a $\mathrm{Fe}^{3+} / \mathrm{Fe}^{2+}$ high concentration ratio. Conversely, microbial metabolism requires $\mathrm{Fe}^{2+}$ oxidation, thereby leading to a relatively lower electric potential, namely a lower $\mathrm{Fe}^{3+} / \mathrm{Fe}^{2+}$ concentration ratio, which corresponds to a better condition.

Moreover, $\mathrm{Cu}$ bioleaching from chalcopyrite is still not widely commercialized because there is a decrease in the extraction speed decline due to the formation of passivation layers during extraction. The passivation layer cannot be viewed since it is excessively thin to observe via a microscope, and thus the presence and effect of a passivation layer are predicted with indirect methods. Frequently used techniques include the following: 1) when external voltage is applied to chalcopyrite, electric current value appears due to the extraction following the voltage increase. The point where the value suddenly falls is observed; 2) the point at which the leaching amount falls is observed while tracking the evolution of leaching reaction over time. Jarosite is suspected as the major substance that forms the passivation layer, which in turn decreases the leaching reaction. It appears to occur frequently in a high electric potential condition when the $\mathrm{pH}$ level of the solution locally rises. A few recent studies argued that the cause of reduced $\mathrm{Cu}$ recovery from chalcopyrite does not correspond to the presence of the passivation layer although the general property of chalcopyrite corresponds to a semiconductor.

\section{Acknowledgements}

This work was supported by the Korea Institute of Energy Technology Evaluation and Planning (KETEP), granted financial resource from the Ministry of Trade Industry \& Energym, Republic of Korea (No. 20182510102420).

\section{References}

Acero, P., Cama, J., Ayora, C., and Asta, M., 2009, Chalcopyrite dissolution rate law from $\mathrm{pH} 1$ to 3. Geologica Acta, v. 7, pp. 389-397.

Adebayo, A., Ipinmoroti, K., and Ajayi, O., 2003, Dissolution kinetics of chalcopyrite with hydrogen peroxide in sulphuric acid medium. Chemical Biochemical Engineering Quarterly, v. 17, pp. 213-218.

Ahmadi, A., Schaffie, M., Petersen, J., Schippers, A., and Ranjbar, M., 2011, Conventional and electrochemical bioleaching of Chalcopyrite concentrates by moderately thermophilic bacteria at high pulp density. Hydrometallurgy, v. 106, pp. 84-92.

Aydoğan, S., Uçar, G., and Canbazoglu, M., 2006a, Dissolution kinetics of chalcopyrite in acidic potassium dichromate solution. Hydrometallurgy, v. 81, pp. $45-51$.

Aydoğan, S., Erdemoğlu, M., Aras, A., Uçar, G., and Özkan, A., 2006b, Dissolution kinetics of celestite $\left(\mathrm{SrSO}_{4}\right)$ in $\mathrm{HCl}$ solution with $\mathrm{BaCl}_{2}$.
Hydrometallurgy, v. 84, pp. 239-246.

Carneiro, M.F.C., and Leão, V.A., 2007, The role of sodium chloride on surface properties of chalcopyrite leached with ferric sulphate. Hydrometallurgy, v. 87, pp. 73-79.

Chmielewski, T., and Kaleta, R., 2011, Galvanic interactions of sulfide minerals in leaching of flotation concentrate from Lubin concentrator. Physicochemical Problems of Mineral Processing, v. 46, pp. 21-34.

Córdoba, E.M., Muñoz, J.A., Blázquez, M.L., González, F., and Ballester, A., 2008, Leaching of chalcopyrite with ferric ion. Part I: General aspects. Hydrometallurgy, v. 93, pp. 81-87.

Córdoba, E.M., Muñoz, J.A., Blázquez, M.L., González, F., and Ballester, A., 2008, Leaching of chalcopyrite with ferric ion. Part III: Effect of redox potential on the silver-catalyzed process. Hydrometallurgy, v. 93, pp. 97-105.

Crundwell, F.K., 2015, The semiconductor mechanism of dissolution and the pseudo-passivation of chalcopyrite. Canadian Metallurgical Quarterly, v. 54, pp. 279-288.

Debernardi, G., and Carles, C., 2013, Chemical-electrochemical approaches to the study passivation of chalcopyrite. Mineral Processing and Extractive Metallurgy Review, v. 34, pp. 10-41.

D’Hugues, P., Foucher, S., Gallé-Cavalloni, P., and Morin, D., 2002, Continuous bioleaching of chalcopyrite using a novel extremely thermophilic mixed culture. International Journal of Mineral Processing, v. 66, pp. $107-119$.

Dixon, D.G., Mayne, D.D., and Baxter, K.G., 2008, GALVANOX ${ }^{\mathrm{TM}}-\mathrm{a}$ novel galvanically-assisted atmospheric leaching technology for copper concentrates. Canadian Metallurgical Quarterly, v. 47, pp. 327-336.

Dong, T., Hua, Y., Zhang, Q., and Zhou, D., 2009, Leaching of chalcopyrite with Brønsted acidic ionic liquid. Hydrometallurgy, v. 99, pp. 33-38.

Dreisinger, D., and Abed, N., 2002, A fundamental study of the reductive leaching of chalcopyrite using metallic iron. Part I: Kinetic analysis. Hydrometallurgy, v. 66, pp. 37-57.

Espiari, S., Rashchi, F., and Sadrenezhaad, S.K., 2006, Hydrometallurgical treatment of tailings with high zinc content. Hydrometallurgy, v. 82, pp. 54-62.

Feng, S., Yang, H., Zhan, X., and Wang, W., 2014, Novel integration strategy for enhancing chalcopyrite bioleaching by Acidithiobacillus sp. in a 7-L fermenter. Bioresource Technology, v. 161, pp. 371-378.

Fuentes-Aceituno, J.C., Lapidus, G.T., and Doyle, F.M., 2008, A kinetic study of the electro-assisted reduction of chalcopyrite. Hydrometallurgy, v. 92, pp. 26-33.

Ghahremaninezhad, A., Radzinski, R., Gheorghiu, T., Dixon, D.G., and Asselin, E., 2015, A model for silver ion catalysis of chalcopyrite $\left(\mathrm{CuFeS}_{2}\right)$ dissolution. Hydrometallurgy, v. 155, pp. 95-104.

Hackl, R.P., Dreisinger, D.B., Peters, E., and King, J.A., 1995, Passivation of chalcopyrite during oxidative leaching in sulfate media. Hydrometallurgy, v. 39, pp. 25-48.

Harmer, S.L., Thomas, J.E., Fornasiero, D., and Gerson, A.R., 2006, The evolution of surface layers formed during chalcopyrite leaching. Geochimica et Cosmochimica Acta, v. 70, pp. 4392-4402.

Hirato, T., Kinishita, M., Awakura, Y., and Majima, H., 1986, The leaching of chalcopyrite with ferric chloride. Metallurgical Transactions, v. 17, pp. 19-28.

Hirato, T., Majima, H., and Awakura, Y., 1987, The leaching of chalcopyrite with ferric sulphate. Metallurgical Transactions B, v. 18, pp. 489-496.

Hiroyoshi, N., Arai, M., Miki, H., Tsunekawa, M., and Hirajima, T., 2002, A new reaction model for the catalytic effect of silver ions on chalcopyrite leaching in sulfuric acid solutions. Hydrometallurgy, v. 63, pp. 257-267.

Holmes, P.R., and Crundwell, F.K., 1995, Kinetic aspects of galvanic interactions between minerals during dissolution. Hydrometallurgy, v. 39, pp. 353-375.

Ikiz, D., Gülfen, M., and AydIn, A. O., 2006, Dissolution kinetics of primary chalcopyrite ore in hypochlorite solution. Mineral Engineering, v. 19 , pp. $972-974$. 
Kimball, B.E., Rimstidt, J.D., and Brantley, S.L., 2010, Chalcopyrite dissolution rate laws. Applied Geochemistry, v. 25, pp. 972-83.

Klauber, C., 2008, A critical review of the surface chemistry of acidic ferric sulphate dissolution of chalcopyrite with regards to hindered dissolution. International Journal of Mineral Processing, v. 86, pp. 1-17.

Lee, S.H., 2017a, Review on electrical mechanisms of $\mathrm{Cu}$ bioleaching from chalcopyrite. Journal of the Korean Society of Mineral and Energy Resources Engineers, v. 54, pp. 690-699. (in Korean)

Lee, S.H., 2017b, Characteristics and countermeasures of the passivation layers in chalcopyrite bioleaching. Journal of the Korean Society of Mineral and Energy Resources Engineers, v. 54, pp. 700-709. (in Korean)

Liang, C.L., Xia, J.L., Zhao, X.J., Yang, Y., Gong, S.Q., Nie, Z.Y., Ma, C.Y., Zheng, L., Zhao, Y.D., and Qiu, G.Z., 2010, Effect of activated carbon on chalcopyrite bioleaching with extreme thermophile Acidianus manzaensis. Hydrometallurgy, v. 105, pp. 179-185.

Li, J., Kawashima, N., Kaplun, K., Absolon, V.J., and Gerson, A.R., 2010, Chalcopyrite leaching: the rate controlling factors. Geochimica et Cosmochimica Acta, v. 74, pp. 2881-2893.

Li, Y., Kawashima, N., Li, J., Chandra, A.P., and Gerson, A.R., 2013, A review of the structure, and fundamental mechanisms and kinetics of the leaching of chalcopyrite. Advances in Colloid and Interface Science, v. 197-198, pp. 1-32.

Martin, J., Leahy, M., and Schwarz, P., 2009, Modelling jarosite precipitation in isothermal chalcopyrite bioleaching columns. Hydrometallurgy, v. 98, pp. 181-191.

Martínez-Gómez, V.J., Fuentes-Aceituno, J.C., Pérez-Garibay, R., and Lee, J.-C., 2016, A phenomenological study of the electro-assisted reductive leaching of chalcopyrite. Hydrometallurgy, v. 164, pp. 54-63.

Nakazawa, H., Fujisawa, H., and Sato, H., 1998, Effect of activated carbon on the bioleaching of chalcopyrite concentrate. International Journal of Mineral Processing, v. 55, pp. 87-94.

Nicol, M.J., 2016, Photocurrents at chalcopyrite and pyrite electrodes under leaching conditions. Hydrometallurgy, v. 163, pp. 104-107.

Nicol, M.J., Miki, H., and Zhang, S., 2017, The anodic behaviour of chalcopyrite in chloride solutions: voltammetry. Hydrometallurgy, v. 171, pp. 198-205.

Osseo-Asare, K., 1992, Semiconductor electrochemistry and hydrometallurgical dissolution processes. Hydrometallurgy, v. 29, pp. 61-90.

Parker, A.J., Paul, R.L., and Power, G.P., 1981, Electrochemical aspects of leaching copper from chalcopyrite in ferric and cupric salt solutions. Australian Journal of Chemistry, v. 34, pp. 13-34.

Panda, S., Akcil, A., Pradhan, N., and Deveci, H., 2015, Current scenario of chalcopyrite bioleaching: a review on the recent advances to its heap-leach technology. Bioresource Technology, v. 196, pp. 694-706.

Safari, V., Arzpeyma, G., Mostoufi, N., and Rashci, F., 2009, A shrinking particle-shrinking core model for leaching of a zinc ore containing silica. Journal of Mineral Processing, v. 93, pp. 79-83.

Zhao, H., Wang, J., Yang, C., Hu, M., Gan, X., Tao, L., Qin, W., and Qiu, G., 2015, Effect of redox potential on bioleaching of chalcopyrite by moderately thermophilic bacteria: an emphasis on solution compositions. Hydrometallurgy, v. 151, pp. 141-150.

Zhao, H., Wang, J., Gan, X., Hu, M., Tao, L., Qin, W., and Qiu, G., 2016, Role of pyrite in sulfuric acid leaching of chalcopyrite: an elimination of polysulfide by controlling redox potential. Hydrometallurgy, v. 164, pp. 159-165.

Zeng, W., Qiu, G., Zhou, H., Liu, X., Chen, M., Chao, W., Zhang, C., and Peng, J., 2010, Characterization of extracellular polymeric substances extracted during the bioleaching of chalcopyrite concentrate. Hydro- metallurgy, v. 100, pp. 177-180.

Zeng, W., Qiu, G., Zhou, H., and Chen, M., 2011, Electrochemical behaviour of massive chalcopyrite electrodes bioleached by moderately thermophilic microorganisms at $48^{\circ} \mathrm{C}$. Hydrometallurgy, v. 105, pp. 259-263.

Zhou, H-B., Zeng, W-M., Yang, Z-F., Xie, Y-J., and Qiu, G-Z., 2009, Bioleaching of chalcopyrite concentrate by a moderately thermophilic culture in a stirred tank reactor. Bioresource Technology, v. 100, pp. 515-520.

Zhou, S., Gan, M., Zhu, J., Li, Q., Jie, S., Yang, B., and Liu, X., 2015, Catalytic effect of light illumination on bioleaching of chalcopyrite. Bioresource Technology, v. 182, pp. 345-352.

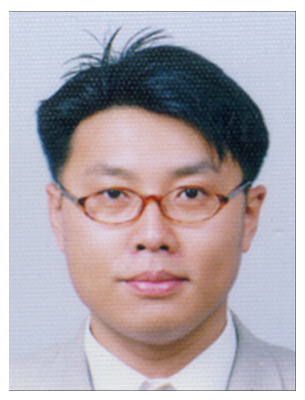

Injae Yang obtained his M.S. from the Seoul National University in 1993. He worked as an engineer of Hyundai Engineering \& Construction Company and joined the Korea Mine Reclamation Corporation (MIRECO) in 2006 and became a Research Director at the MIRECO in 2018. He has a long experience on geotechnical engineering design in Sambo Engineering and Daehan Consultants. His work is in the field of prevention of ground subsidence, and the development of geopark model particularly in the field of abandoned mine area. He is currently member of Board of Directors of Korean Society of Rock Mechanics and Rock Engineering (KSRM).

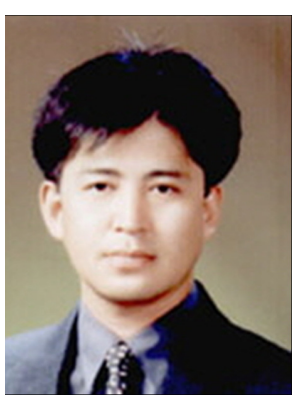

Seungjin Choi obtained his Ph.D. degree in Earth System Science from the Yonsei University of Korea in 2007. He worked as an engineer at the Korea Rural Corporation (KRC) in his early days, and joined the Korea Mine Reclamation Corporation (MIRECO) in 2006. He has a long experience on geotechnical engineering and environmental geology for 24 years as a geologist in KRC \& MIRECO. His work is in the field of remediation of soil and groundwater in rural and abandoned mine area. He is a member of Board of Directors of Korean Society of Soil and Groundwater Environment (KoSSGE). And he is currently General Director of the Institute of Mine Reclamation Technology \& Global Business of MIRECO, Korea.

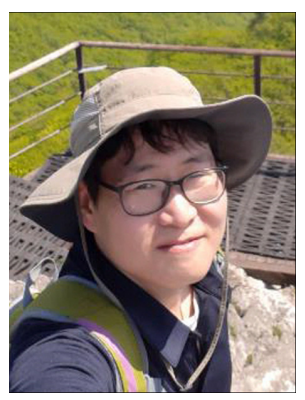

Jayhyun Park obtained his Ph.D. from the Hanyang University of Seoul in 2006 . He worked as a student researcher in the Korea Institute of Geoscience and Mineral Resources (KIGAM) during his doctorial course and joined the Korea Mine Reclamation Corporation (MIRECO) in 2006. He has a teaching experience as adjunct professor at Hanyang University in S. Korea. His work is in the field of mine reclamation plan, eco-friendly mineral beneficiation, bio leaching of sulphide minerals, and desulfurization of heavy metal contained mine tailings. He is currently team leader of Institute of mine reclamation technology center in MIRECO. 